\title{
Chitosan in Combination with Chemical Fertilizer on Agronomic Traits and Some Physiological Responses Relating to Yield Potential of Rice (Oryza sativa $\mathrm{L}$.)
}

\author{
${ }^{1}$ Suchada Boonlertnirun, ${ }^{1}$ Raweewun Suvannasara, \\ ${ }^{2}$ Prapurt Promsomboon and ${ }^{1}$ Kitti Boonlertnirun \\ ${ }^{1}$ Department of Plant Science, Faculty of Agricultural Technology and Agro-Industry, \\ Rajamangala University of Technology Suvarnabhumi, \\ Pranakhon Sri Ayuttaya Province, 13000, Thailand \\ ${ }^{2}$ Rajamangala University of Technology Tawan-ok, Sri Racha, \\ Chon Buri Province, 20110, Thailand
}

\begin{abstract}
Chitosan can be used to stimulate growth and enhance yield in many crop species. This experiment was to study efficacy of chitosan as fertilizer supplement to stimulate growth and enhance rice yield. The experimental design was randomized complete block design with four treatments, i.e., Tr1; chitosan at the concentration of $80 \mathrm{mg} \mathrm{L}^{-1}$ in combination with mixed chemical fertilizer between urea (46-0-0) and 16-20-0 at the rate of $312.5 \mathrm{~kg} \mathrm{ha}^{-1}, \operatorname{Tr} 2$; mixed chemical fertilizer between urea (46-0-0) and 16-20-0 at the rate of $312.5 \mathrm{~kg}$ $\mathrm{ha}^{-1}, \operatorname{Tr} 3$; chitosan spraying at the concentration of $80 \mathrm{mg} \mathrm{L}^{-1}$ and $\operatorname{Tr} 4$; no application of chitosan and mixed chemical fertilizer and five replications was performed. It was conducted in a greenhouse of Agricultural Technology and Agro-Industry Faculty, Rajamangala University of Technology Suvarnnaphumi, during April to August, 2011. The results revealed that application of chitosan in combination with mixed chemical fertilizer showed positive effects on leaf greenness, dry weight, yield and yield components of rice plants, however did not significantly differ from those of application of mixed chemical fertilizer alone. Application of chitosan alone and no application of both mixed chemical fertilizer and chitosan had poor effects on growth, yield and yield components of rice plants. From this study, it is suggested that rice yield can be enhanced by application of chitosan in combination with chemical fertilizer (as farmer practices).
\end{abstract}

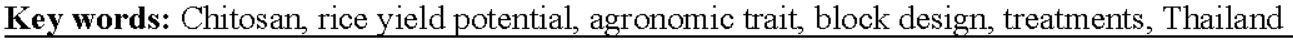

\section{INTRODUCTION}

Rice (Oryza sativa L.) is very important economic crop in Thailand because of the most valuable exported product. Currently, rice yield is strongly demanded both inside and outside the country but yield per area is still low resulted in lack of product for supplying. Now-a-days, rice production costs are rapidly increased due to much more chemical fertilizer uses, particularly nitrogen fertilizer. Chemical fertilizer application in rice production is very important to promote growth and enhance yield. Fertilizer application in excess of crop requirements contributes to the increased levels of chemical substance in the soil profile and ground water. Reducing $\mathrm{N}$ application rate by $5 \%$ less than that of the required rate to achieve maximum yield reduces $\mathrm{NO}_{3}$ - leaching by $40-45 \%$ (Sexton et al., 1996).

Chitosan, a natural biopolymer contained a lot of nitrogen molecules can enhance germination index and shoot and root dry weight (Guan et al., 2009). It also promotes seedling growth, accelerates the first flowering date of several ornamental plants (Ohta et al., 2004), stimulates plant growth and enhances yield of crop species such as Oryza sativa L. and Glycine max L. (Boonlertnirun et al., 2008; Zheng et al., 2005). Furthermore, it has been shown to trigger immune system to resist plant disease in many plant species (Nandeeshkumar et al., 2008) and can be absorbed to the root after being decomposed by bacteria in the soil. Application of chitosan in agriculture, even without chemical fertilizer can increase the microbial population by large numbers and transforms organic nutrient into inorganic nutrient which is easily absorbed by the plant roots (Somashekar and Joseph, 1996; Bolto et al., 2004). Chitosan is reported to use as the nutrient for the soybean cultivation when the nitrogen is insufficient (Zheng et al., 2005). Application of Pseudomonas fluorescens strains, CHAO + chitin significantly improved

Corresponding Author: K. Boonlertnirun, Department of Plant Science, Faculty of Agricultural Technology and Agro-Industry, Rajamangala University of Technology Suvarnabhumi, Pranakhon Sri Ayuttaya Province, 13000, Thailand 
the $\mathrm{N}, \mathrm{P}$ and $\mathrm{K}$ contents of banana leaves when compared to untreated (Kavino et al., 2010). The objective was to study efficacy of chitosan as fertilizer supplement to stimulate growth and enhance rice yield.

\section{MATERIALS AND METHODS}

Experimental design and treatment: Randomized complete block design with four treatments, i.e., Trl, chitosan at the concentration of $80 \mathrm{mg} \mathrm{L}^{-1}$ in combination with mixed chemical fertilizer between urea (46-0-0) and $16-20-0$ at the rate of $312.5 \mathrm{~kg} \mathrm{ha}^{-1}, \operatorname{Tr} 2$, mixed chemical fertilizer between urea (46-0-0) and 16-20-0 at the rate of $312.5 \mathrm{~kg} \mathrm{ha}^{-1}, \operatorname{Tr} 3$, chitosan spraying at the concentration of $80 \mathrm{mg} \mathrm{L}^{-1}$ and $\operatorname{Tr} 4$, no application of chitosan and mixed chemical fertilizer and five replications were performed.

Chitosan and plant preparation: Oligomer chitosan with $90 \%$ of degree of deacetylation from shrimp shell was used in this experiment. Pot experiment was conducted in an open-ended outdoor greenhouse with daily maximum and minimum temperatures of 34 and $23^{\circ} \mathrm{C}$, respectively. Rice seeds cv., Pathum Thanee 1 was planted in $60 \mathrm{~cm}$ diameter cement tank containing clay soil which was analyzed chemical properties $(\mathrm{pH}=7 \%, \mathrm{OM}=2.35$ (moderate), aval., $\mathrm{P}=88 \mathrm{mg} \mathrm{kg}^{-1}$ (very high), exch., $\mathrm{K}=230 \mathrm{mg} \mathrm{kg}^{-1}$ (very high)). Only four healthy seedlings per treatment per replication were selected to use as representative for data recording. When rice plant age was 25-30 days after planting, the first chitosan spraying was done, after that chitosan was again sprayed at 7-10 days interval for 4 times through crop season. Mixed chemical fertilizer application at the rate as mentioned earlier was split to apply only $\operatorname{Tr} 1$ and $\operatorname{Tr} 2$ 3 times at 15,35 and 55 days after planting. This experiment was carried out at Rajamangala University of Technology Suvarnabhumi during April to August, 2011. All data were subjected to ANOVA by MSTAT and treatment mean comparison was done by the use of Least Significant Difference (LSD).

\section{RESULTS AND DISCUSSION}

Plant height: Plant height at harvest of rice plants was not significantly influenced by different application methods. However, application of chitosan in combination with mixed chemical fertilizer tended to promote plant height greater than the other applications. This may be most components of chitosan are nitrogen molecule which is an important nutrient for stimulating growth and plant height. No application of mixed chemical fertilizer and

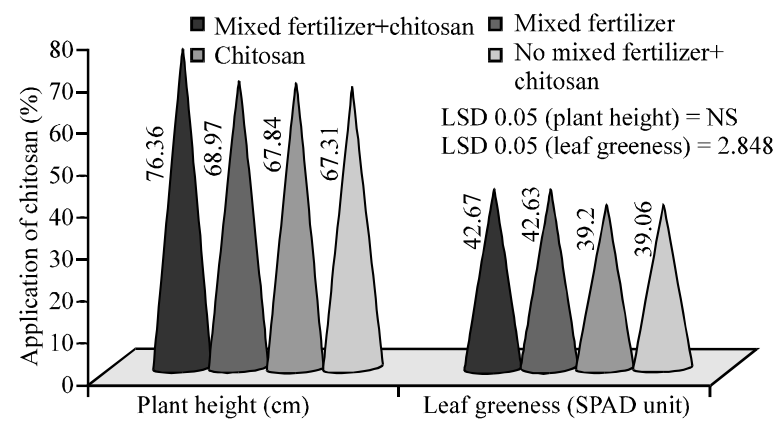

Fig. 1: Effects of chitosan, mixed chemical fertilizer and their combinations on plant height and leaf greenness

chitosan showed the lowest plant height (Fig. 1). Chitosan oligomer strongly increased height of coffee seedlings (Dzung et al., 2011). Elexa (containing 4\% chitosan) treated to pearl millet seeds under greenhouse condition increased plant height (Sharathchandra et al., 2004). Polymeric chitosan at 10,20 and $40 \mathrm{mg} \mathrm{L}^{-1}$ significantly enhanced the average plantlet shoot length of hybrid Dendrobium orchids (Pornpienpakdee et al., 2010).

Leaf greenness: Leaf greenness (SPAD value) of rice leaves was measured by chlorophyll meter (SPAD 502) at harvest and found that different application methods were significantly different on leaf greenness of rice plants. Application of chitosan in combination with mixed chemical fertilizer showed high SPAD value over than the others but did not differ from that of mixed chemical fertilizer application (Fig. 1). Boonlertnirun et al. (2010) reported that field corn applied with chitosan at the concentration of $80 \mathrm{mg} \mathrm{L}^{-1}$ before subjecting to hypoxia tended to retain leaf greenness over than that of no chitosan. Moreover, application of chitosan significantly promoted leaf greenness of waxy corn and significantly differed from the control (Boonlertnirun et al., 2011).

The lowest SPAD value was detected from treatment with no application of chitosan and mixed chemical fertilizer.

Chlorophyll content: Chlorophyll a, b and total chlorophyll were not significantly different among different application methods. Considering chlorophyll a, treatments applied with chitosan tended to produce chlorophyll a over than untreated chitosan treatment whereas higher content of chlorophyll b was usually found in treatment applied with mixed chemical fertilizer, however all treatments were not significantly different. In regard to total chlorophyll content, application of chitosan in combination with mixed chemical fertilizer 


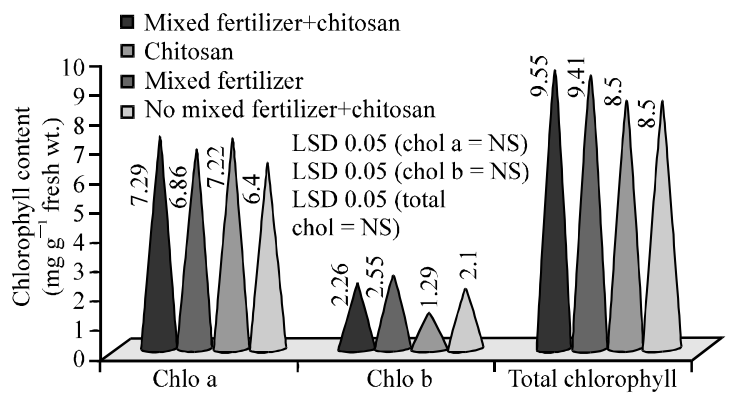

Fig. 2: Effects of chitosan, mixed chemical fertilizer and their combinations on chlorophyll content

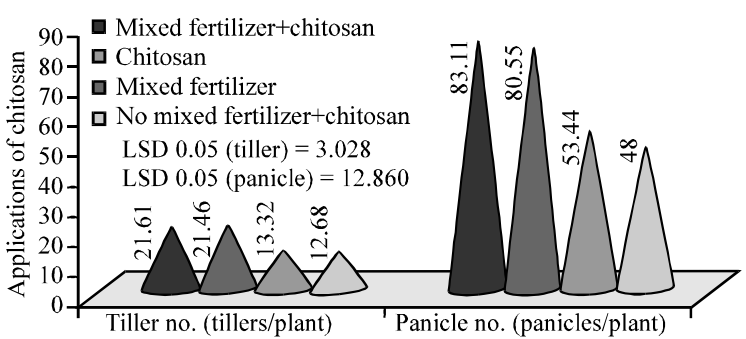

Fig. 3: Effects of chitosan, mixed chemical fertilizer and their combinations on tiller numbers and panicle numbers per plant

tended to sustain chlorophyll greater than those of the others (Fig. 2). Xing et al. (2011) reported that chitosan coating enriched with cinnamon oil could maintain chlorophyll content in sweet pepper (Capsicum annuum L.) stored at $8^{\circ} \mathrm{C}$ for 35 days better than untreated. Application of chitosan oligomer in field condition increased chlorophyll content in leaves of coffee seedlings up to $15.36 \%$ (Dzung et al., 2011).

Tiller number per plant: Different application methods significantly affected tiller number per plant, the maximum tiller numbers were obtained from application of chitosan in combination with mixed chemical fertilizer but did not differ from that of mixed chemical fertilizer application. Ramos-Garcia et al. (2009) reported that gladiolus corms were accelerated in approximately 4 days after applying commercial chitosan Biorend 1 at $1.5 \%$ alone or combined with hot water at $50^{\circ} \mathrm{C}$. Plant numbers of faba bean were increased after applying water soluble chitosan at 100 ppm (El-Sawy et al., 2010). No application mixed chemical fertilizer and chitosan gave the lowest tillers when compared to the other treatments (Fig. 3).

Panicle number per plant: Numbers of panicles were significantly influenced by different application methods.

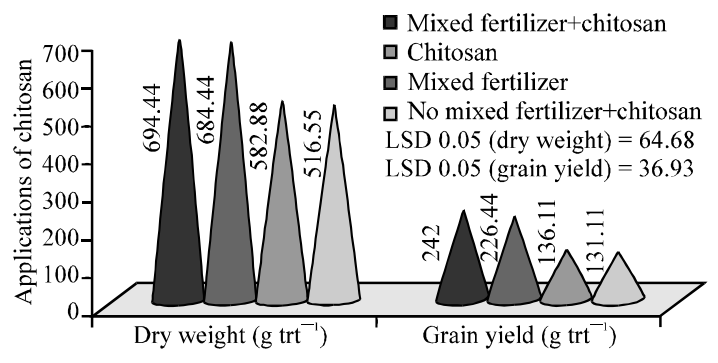

Fig. 4: Effects of chitosan, mixed chemical fertilizer and their combinations on dry weight and grain yield

Application of chitosan in combination with mixed chemical fertilizer and application of mixed chemical fertilizer alone did not significantly differ in terms of panicle numbers, however the highest panicle numbers were achieved from chitosan application in combination with mixed chemical fertilizer.

Abdel-Mawgoud et al. (2010) reported that application of chitosan at $2 \mathrm{mg} \mathrm{L}^{-1}$ improved yield components (number and weight) of strawberry plants. Panicle numbers of rice were increased after spraying chitosan at the concentration of $0.4 \mathrm{~g} / 50 \mathrm{cc}$ of water (Lu et al., 2002).

Chitosan solution at the concentration of $0.15 \%(\mathrm{w} / \mathrm{v})$ induced a significant increase in the number of seeds and pods per plant of Phaseolus vulgaris L. (Iriti et al., 2010). The lowest panicle numbers were obtained from no mixed chemical fertilizer and chitosan application alone, respectively (Fig. 3).

Dry weight: Dry weight of rice plants was significantly different with different methods of application. The maximum dry weight was obtained from application of chitosan in combination with mixed chemical fertilizer. Slightly different dry weight was found between application of chitosan with mixed chemical fertilizer and application of mixed chemical fertilizer alone, however no significant difference was detected. Fresh and dry weight of strawberry were increased after foliar application of chitosan 3 times with 4 weeks interval at the concentration of $2 \mathrm{cc} \mathrm{L}^{-1}$ of water (Abdel-Mawgoud et al., 2010). Water soluble chitosan at $100 \mathrm{ppm}$ could promote biological yield of faba bean (El-Sawy et al., 2010). Application of chitosan alone and no application of mixed chemical fertilizer and chitosan showed rather low dry weight and was not significant (Fig. 4) .

Grain yield: Grain yield of rice plants showed significant differences among different application methods. 
Application of chitosan in combination with mixed chemical fertilizer could increase grain yield greater than the others but did not differ from application of mixed chemical fertilizer alone. $P$. fluorescens strain, CHAO in combination with chitin had the potential to increase yield of banana plants under perennial cropping systems (Kavino et al., 2010). Chitosan application had a tendency to increase grain yield of rice plants over than untreated (Boonlertnirun et al., 2010).

The lower grain yield was obtained from no application of mixed chemical fertilizer and chitosan and chitosan application alone and was not significantly different between them (Fig. 4).

\section{CONCLUSION}

According to the results, it can be found that application of chitosan in combination with less chemical fertilizer should be used in rice production because positive trend to promote growth and enhance rice yield is obviously observed in this study.

\section{ACKNOWLEDGEMENT}

The researchers would like to greatly appreciate and thank Rajamangala University of Technology Suvarnabhumi for providing some facilities and granting research budgets for this study.

\section{REFERENCES}

Abdel-Mawgoud, A.M.R., A.S. Tantawy, M.A. El-Nemr and Y.N. Sassine, 2010. Growth and yield responses of strawberry plants to chitosan application. Eur. J. Sci. Res., 39: 161-168.

Bolto, B., D. Dixon and R. Eldridge, 2004. Ion exchange for the removal of natural organic matter. React. Funct. Polym., 60: 171-182.

Boonlertnirun, S., C. Boonraung and R. Suvanasara, 2008. Application of chitosan in rice production. J. Met. Mater. Mine., 18: 47-52.

Boonlertnirun, S., S. Mechoui and E. Sarobol, 2010. Physiological and morphological responses of field corn seedlings to chitosan under hypoxic conditions. Sci. Asia, 36: 89-93.

Boonlertnirun, S., C. Boonraung, R. Suvannasara P. Promsomboon and K. Boonlertnirun, 2011. Chitosan application for reducing chemical fertilizer uses in rice production. World Acad. Sci. Eng. Technol., 80: 909-913.
Dzung, N.A., V.T.P. Khanh and T.T. Dzung, 2011. Research on impact of chitosan oligomers on biophysical characteristics, growth, development and drought resistance of coffee. Carbohydr. Polym., 84: 751-755.

El-Sawy, N.M., H.A.A. El-Rehim, A.M. Elbarbary and E.S.A. Hegazy, 2010. Radiation-induced degradation of chitosan for possible use as a growth promoter in agricultural purposes. Carbohydr. Polym., 79: 555-562.

Guan, Y.J., J. Hu, X.J. Wang and C.X. Shao, 2009. Seed priming with chitosan improves maize germination and seedling growth in relation to physiological changes under low temperature stress. J. Zhejiang Univ. Sci. B, 10: 427-433.

Iriti, M., G. Castorina, S. Vitalini, I. Mignani, C. Soave, G. Fico and F. Faoro, 2010. Chitosan-induced ethylene-independent resistance does not reduce crop yield in bean. Biol. Control, 54: 241-247.

Kavino, M., S. Harish, N. Kumar, D. Saravanakumar and R. Samiyappan, 2010. Effect of chitinolytic PGPR on growth, yield and physiological attributes of banana (Musa spp.) under field conditions. Applied Soil Ecol., 45: 71-77.

Lu, J., C. Zhang, G. Hou, J. Zhang and C. Wan et al., 2002. The biological effects of chitosan on rice growth. Acta Agric. Shanghai, 18: 31-34.

Nandeeshkumar, P., J. Sudisha, K.K. Ramachandra, H.S. Prakash, S.R. Niranjana and S.H. Shekar, 2008. Chitosan induced resistance to downy mildew in sunflower caused by Plasmopara halstedii. Physiol. Mol. Plant Pathol., 72: 188-194.

Ohta, K., S. Morishita, K. Suda, N. Kobayashi and T. Hosoki, 2004. Effects of chitosan soil mixture treatment in the seedling stage on the growth and flowering of several ornamental plants. J. Jpn. Soc. Hortic. Sci., 73: 66-68.

Pompienpakdee, P., R. Singhasurasak, P. Chaiyasap, R. Pichyangkura, R. Bunjongrat, S. Chadchawan and P. Limpanavech, 2010. Improving the micropropagation efficiency of hybrid Dendrobium orchids with chitosan. Sci. Hortic., 124: 490-499.

Ramos-Garcia, M., S. Ortega-Centeno, A.N. HernandezLauzardo, I. Alia-Tejacal, E. Bosquez-Molina and S. Bautista-Banos, 2009. Response of gladiolus (Gladiolus spp) plants after exposure corms to chitosan and hot water treatments. Sci. Hortic., 121: 480-484.

Sexton, B.T., J.F. Moncrief, C.J. Rosen, S.C. Gupta and H.H. Cheng, 1996. Optimizing nitrogen and irrigation inputs for corn based on nitrate leaching and yield on a coarse-textured soil. J. Environ. Qual., 25: 982-992. 
Sharathchandra, R.G., S.N. Raj, N.P. Shetty, K.N. Amruthesh and H.S. Shetty, 2004. A Chitosan formulation Elexa induces downy mildew disease resistance and growth promotion in pearl millet. Crop Prot., 23: 881-888.

Somashekar, D. and R. Joseph, 1996. Chitosanaseproperties and applications: A review. Bioresour. Technol., 55: 35-45.
Xing, Y., X. Li, Q. Xu, J. Yun, Y. Lu and Y. Tang, 2011. Effects of chitosan coating enriched with cinnamon oil on qualitative properties of sweet pepper (Capsicum annuum L.). Food Chem., 124: 1443-1450.

Zheng, S.H., K. Nanjo and S. Arima, 2005. Effects of chitosan application to the soil on the growth and seed yield of nodulating and non-nodulating soybean. Coastal Bioenviron., 5: 15-20. 